\section{Pathogenic effects of maternal antinuclear antibodies during pregnancy in women with lupus}

\author{
Rafael Herrera-Esparza, Juan José \\ Bollain-y-Goytia, Esperanza Avalos-Díaz \\ Department of Immunology, UACB - \\ Universidad Autónoma de Zacatecas, \\ México
}

\section{Abstract}

Lupus is an autoimmune disease that primarily affects young women of childbearing age. Fertility rates in lupus patients depend on various factors, including disease activity, nephritis, and the presence of antiphospholipid antibodies; however, after lupus patients become pregnant, different factors may affect the course of pregnancy, such as the production of autoantibodies, pre-existing renal disease, and eclampsia, among others. The placenta is a temporary hemochorial organ that prevents immunological conflict due to exposure to alloantigens at the maternal-fetal interface; placental regulatory $\mathrm{T}$ cells play a major role in maternal-fetal tolerance. Typically, significant amounts of maternal IgG class antibodies cross the placenta and enter the fetal circulation. This transition depends on the distribution of Fc receptors along the syncytiotrophoblast. The production of antinuclear antibodies (ANA) is a hallmark of lupus, and these autoantibodies can form immune complexes that are typically trapped in the placenta during gestation. However, the entry of ANA into the fetal circulation depends on the IgG-ANA concentration and the FCR placental density. Maternal antinuclear antibodies with anti-Ro or anti-La specificity might be pathogenic to the fetus if transfused by the placental pathway and could induce neonatal pathologies, such as neonatal lupus and congenital heart block. Here, we review the experimental and clinical data supporting a pathogenic role for maternal autoantibodies transmitted to the fetus.

\section{Introduction}

Although Malcolm Hargraves defined lupus erythematosus (LE) factor in 1948, the specific autoantibodies and autoreactive lymphocytes in systemic lupus erythematosus (SLE) patients were not described for two decades. The discovery of these molecules indicated the autoimmune nature of this disease. ${ }^{1}$ The prevalence of SLE is approximately 20-150 cases per 100,000 individuals, and the clinical manifestations of this disease result from the failure of immune tolerance mechanisms, resulting in autoimmunity and tissue damage and leading to internal organ dysfunction. ${ }^{2}$ The complex pathophysiological mechanisms of SLE include predisposing MHC genes, epigenetic factors that modulate the transcription of cytokines involved in tissue damage, environmental factors such as UV light, or infectious agents. Sexual hormones, including estrogens or prolactins, are also important, and SLE primarily affects young women. Taken together, these factors and the breakdown of immunological tolerance facilitate disease expression. Lupus primarily affects women of childbearing age, and studies of fertility rates in lupus patients have yielded conflicting results. Cyclophosphamide therapy, anti-phospholipid antibody and/or anti- $\beta$-2-microglobulin production, and pre-existing lupus nephritis have been associated with decreased fertility. ${ }^{3}$

The prevalence of pre-eclampsia during pregnancy may be higher in lupus patients, and high blood pressure, pre-existing nephritis, and the presence of anti-phospholipid antibodies may worsen the prognosis for a healthy pregnancy. ${ }^{3-5}$

\section{Placenta}

The placenta is a temporary hemochorial organ that penetrates the endometrium and develops upon implantation of the blastocyst and is removed at birth. Placental circulatory systems include i) the umbilical cord, ii) the systemic circulatory system and iii) the yolk system. The expression of Hox genes in the allantoic layer is necessary for the functional development of the placenta; these genes are essential for extra-embryonic placental function and embryo survival. For example, the intervention of Hox is critical for expansion of the placentary vasculature. ${ }^{6}$ In addition to the vasculature, the placenta is composed of trophoblastic cells derived from the ectoderm, cells originating from the inner cell mass and epiblast (amnion), and minor cell components from the maternal blood. The amnion is an epithelial cell layer that lies on the surface of the basement membrane, and the chorion is juxtaposed to connective tissue associated with chorionic villi and fetal vessels, which are interdigitated with the chorionic decidua and maternal vessels. The placental villous parenchyma comprises 30 to 60 villi, the functional units that facilitate the diffusion and active transport of nutrients and remove metabolic and cellular wastes from the fetal circulation. On the maternal side, the parenchymal villi consist of a thin basal layer corresponding
Correspondence: Rafael Herrera-Esparza, Department of Immunology, UACB - Universidad Autónoma de Zacatecas, Chepinque 306, Col. Lomas de la Soledad, Zacatecas, 98040, Mexico. Tel/Fax: +52.492.921.1640.

E-mail: rafael.herreraesparza@gmail.com

Key words: lupus pregnancy, ANA transfer, neonatal lupus, lupus placenta, congenital heart block.

Contributions: the authors contributed equally.

Conflict of interests: the authors declare no potential conflict of interests.

Funding: this study was supported through the SEP-PROMEP UAZ-CA5 Autoinmunidad grant.

Received for publication: 12 July 2014.

Revision received: 15 September 2014.

Accepted for publication: 19 September 2014.

This work is licensed under a Creative Commons Attribution NonCommercial 3.0 License (CC BYNC 3.0).

(c) Copyright R. Herrera-Esparza et al., 2014

Licensee PAGEPress, Italy

Rheumatology Reports 2014; 6:5545

doi:10.4081/rr.2014.5545

to the maternal-fetal interface that comprises trophoblast and fibrinoid materials, endometrial stromal fibroblast-like cells, macrophages, arteries, and veins. The umbilical cord and chorion tissue originate from the mesoderm, and the cord is derived from the amniotic epithelium and two arteries and one vein embedded in the Wharton gelatin. ${ }^{7}$

\section{Tolerance and placenta}

The placenta has evolved protective mechanisms to tolerate the maternal immune system and prevent immunological conflict through constant exposure to alloantigens. ${ }^{8}$ Placental regulatory $\mathrm{T}$ cells (Tregs) play a major role in tolerance at the maternal-fetal interface. ${ }^{9}$ Tregs belong to a $\mathrm{CD}^{+}{ }^{+} \mathrm{T}$ cell subset that express the Foxp3 transcription factor; indeed, the congenital or acquired deficiency of Foxp3 results in autoimmunity. There are two pathways for Treg differentiation: the thymic pathway (tTreg) and the peripheral pathway (pTreg). In placental mammals, the expression of Foxp3 outside the thymus depends on the CNS1 enhancer, which binds Smad3 and RAR (retinoic acid receptor) and induces TGF- $\beta$ dependent Foxp3 expression.9,10 CNS1 is a retrotransposon belonging to the SINE MIR 
family of retrotransposons. These transposable elements appeared evolutionarily in the Mesozoic era, and CNS1 was amplified in a radiated manner in placental mammals, marsupials, and monotrems. ${ }^{11}$ CNS1 deficiency in pregnant mice increases fetal resorption, suggesting that during evolution, the CNS1 sequence was generated as a mechanism to strengthen maternal-fetal tolerance. ${ }^{9}$

\section{Physiological transit of maternal immunoglobulin G}

The placental transfer of maternal IgG to the fetus is a physiological fetal protection mechanism that extends through the newborn stage. This protective mechanism is important because the adaptive immune system of the newborn is not exposed to environmental antigens before birth. Among the maternal immunoglobulins, IgG is a unique antibody class that crosses the placenta in significant amounts, and the physiological transit of maternal IgG into the fetus depends on Fc receptor expression in the syncytiotrophoblast (FcyRI, FcyRII, Fc $\gamma$ RIIIa, FcRn, and Fc $\gamma$ RIIIb). For example, in the full-term placenta, FcyRI and FcyRII receptors are predominantly expressed on endothelial and Hofbauer cells, whereas Fc $\gamma$ RIIIa, Fc $\gamma$ RIIIb, and FcRn are widely distributed along trophoblasts; ${ }^{12}$ thus, the passive transfer of maternal antibodies depends on the IgG level and the isotype/FcR ratio. Other miscellaneous factors, such as the integrity of the placenta as a physical barrier, might influence IgG passage (Figure 1). ${ }^{13}$

\section{Antinuclear antibody immune-complex deposition in lupus placenta}

In lupus, autoantibody production against a wide variety of intracellular antigens reflects the autoantigen-mediated polyclonal activation of B cells. Antinuclear antibodies (ANAs) could form immune complexes (IC) in situ that are captured by the placenta during pregnancy, thereby preventing the transfer of maternal ANAs to the fetus. Thus, the placental tissue functions as an immunosorbent that traps ANA-ICs in the trophoblast and amnios. ${ }^{14}$ Subsequently, the ICs could activate the classic complement pathway; C3 and Clq fragments have been frequently observed in the trophoblast, suggesting decreased C3 and C4 lev-

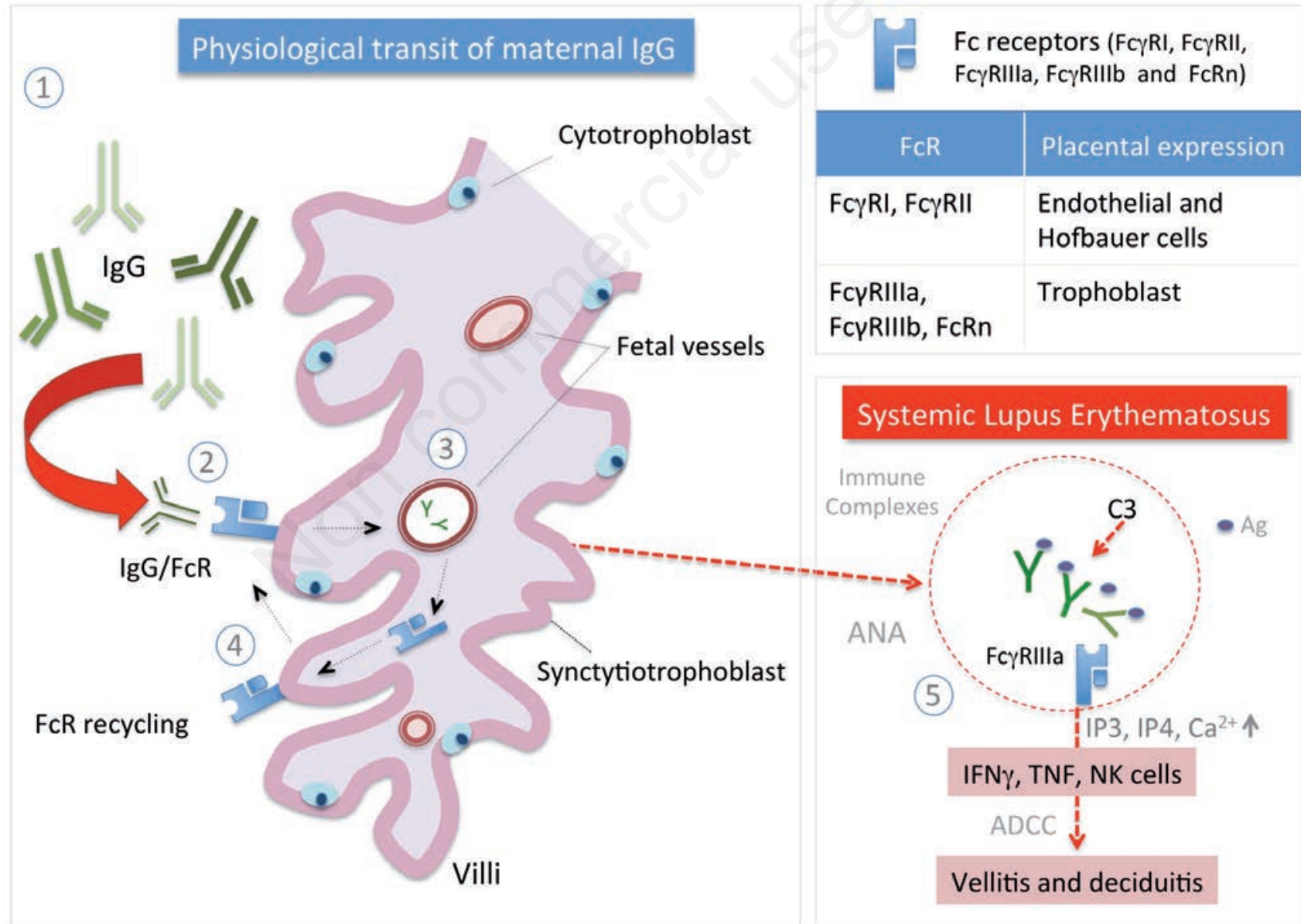

Figure 1. Physiological and pathologic IgG transit through placenta. 1) Normally the maternal IgG may cross the placental barrier. 2) Placental IgG transcytosis occurs via Fc receptors (FcR). 3) Maternal IgG must cross the syncytiotrophoblast and reach the fetal vascular endothelium. 4) After FcR deliver its cargo, the receptor is recycled to form new IgG/FcR complexes. 5) SLE immune complexes (IC) can be trapped in placenta that function as an immunosorbent, IC trapping by FcүRIIIa induces transduction signals that increase intracellular $\mathrm{Ca}^{2+}$, inositol-1,4,5-triphosphate, and phosphatidylinositol (IP4) levels, which promote the activation of IFN- $\gamma$ and TNF, leading to vellitis and deciduitis. 
els in maternal serum, in association with placental dysfunction. ${ }^{15}$ In addition, IC trapping through Fc RIIIa transduces signals that increase intracellular $\mathrm{Ca}^{2+}$, inositol-1,4,5triphosphate, and phosphatidylinositol (IP4) levels, promoting the activation of IFN- $\gamma$ and TNF, which subsequently activate NK cells for antibody dependent cell mediated cytotoxicity (ADCC) cell-mediated reactions leading to vellitis and deciduitis, as commonly observed in the placentas of lupus patients (Figure 1).13,16,17

\section{Transplacental transit of maternal antinuclear antibodies}

In 1954, Bridge and Foley described the passive transfer of maternal ANA to the fetus.
Indeed, these authors reported the placental transfer of LE factor into newborns apparently without clinical consequences, ${ }^{18}$ and this finding has been confirmed by multiple reports. ${ }^{19-22}$ Nathan and Snapper were the first clinicians to describe a potential role for maternal lupus autoantibodies in neonates in a reported case of neonatal thrombocytopenia associated with maternal LE factor. ${ }^{21}$ These observations reflected a natural experiment induced by transplacental transit of maternal autoantibodies. Subsequently, different experimental approaches in rodents have been used to assess the placentary kinetics of ANA (antiDNA, Sm, RNP, La, and anti-Ro), revealing that i) the entry of ANA into the fetus depends on the antibody concentration and FCR placental density; and ii) the transferred ANA is deposited into fetal tissues in a dose-dependent manner. ${ }^{23}$

\section{Neonatal pathology induced by maternal autoantibodies}

In 1954, McCuistion and Schoch described skin lesions in neonates associated with maternal ANA transfer. The authors reported the case of a newborn with discoid lupus whose mother had LE skin lesions, suggesting that the etiological agent was transmitted into the fetus through the placental pathway. ${ }^{24}$ However, this hypothesis was only proved 27 years later in 1981, when Thomas Provost et al. demonstrated that maternal anti-Ro antibodies caused neonatal lupus (NL), which was subsequently confirmed by William Weston et al. .25-27 $^{2}$

In 1977, Chameides contributed to the current understanding of the multiorganic spectrum of NL when he described congenital heart block (CHB) in newborns of mothers with SLE.

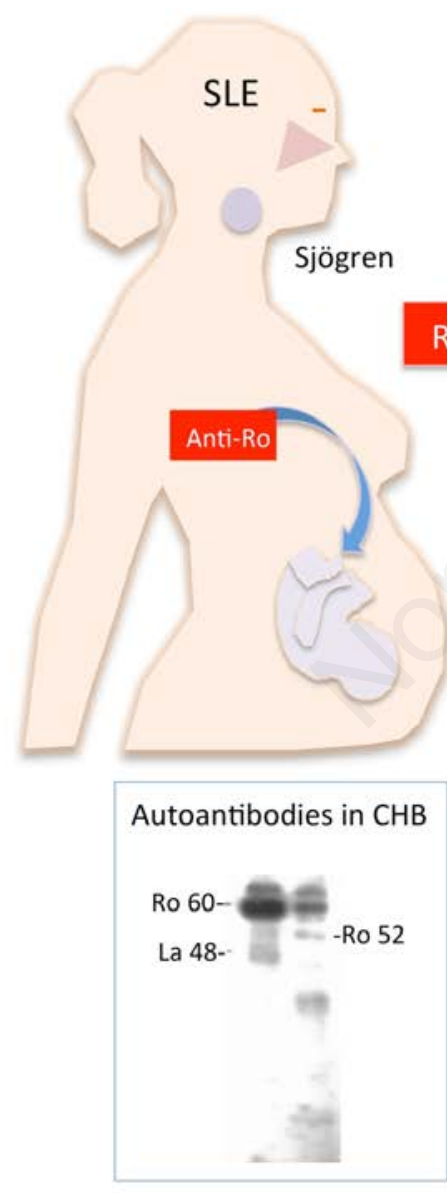

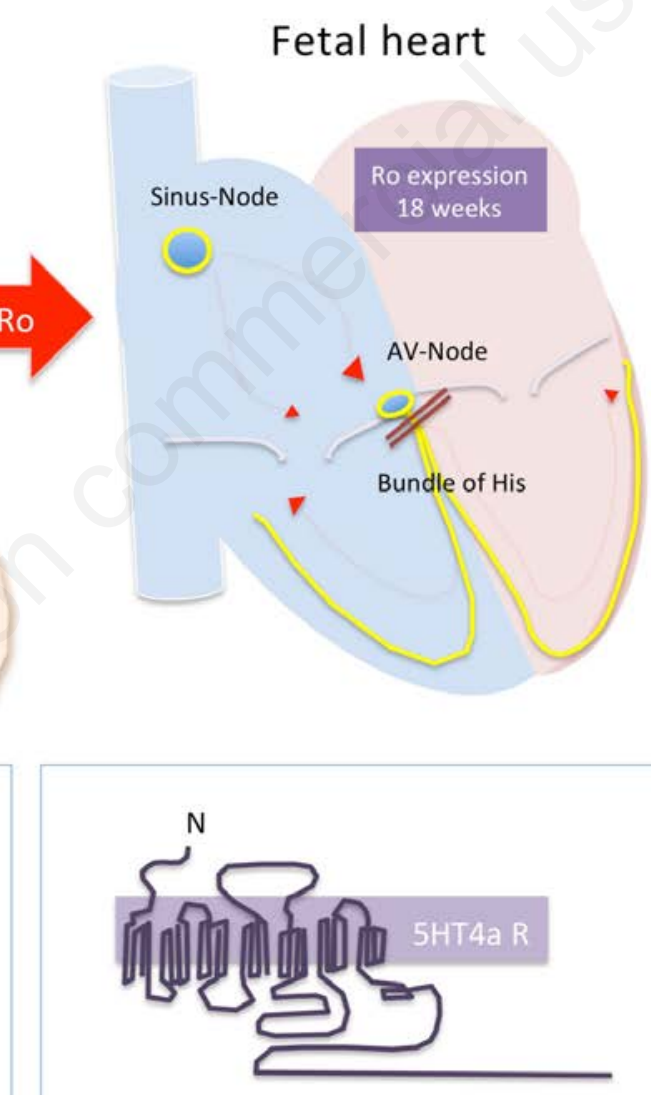

Ro52 /Shared homology in 365-382 residues

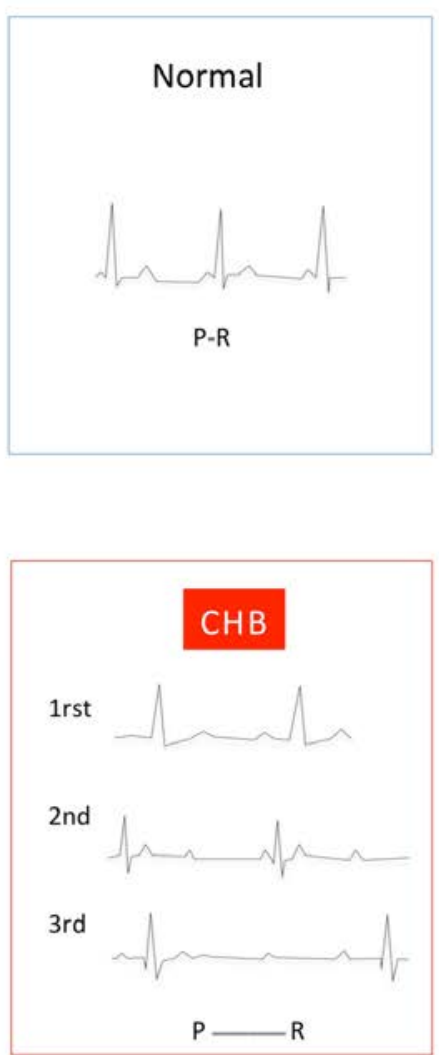

Figure 2. The pathologic mechanisms of CHB induced by maternal anti-Ro/La antibodies. Anti-Ro 52 bind fetal 5-HT4A because Ro52 possesses two sequences (residues 365-382 and 380-396) that share partial homology with the 5-HT4A serotonin receptor. This receptor is widely expressed in the atrial tissue of fetal heart. Maternal anti-Ro antibodies may therefore exert their pathogenic activity by decoupling the excitation-contraction cycles of fetal heart, causing AV blockage of variable degree. 
After observing fibrotic changes in the atrioventricular node during the autopsy of a newborn that died from $\mathrm{CHB}$, this author suggested that these changes influenced this pathology, and the early development of this nodal fibrosis presumably contributed to the observed CHB. ${ }^{28}$ With or without the development of $\mathrm{CHB}, \mathrm{NL}$ is a rare disease that typically depends on the expression of maternal antiRo/La antibodies. ${ }^{29} \mathrm{~A}$ few studies have reported anti-RNP specificity, but this association lacks experimental confirmation.

\section{Ro/SSA molecular complex}

Antibodies to Ro/SSA antigens are serological markers of Sjögren's syndrome and some features of LE, such as subacute cutaneous lupus erythematosus (SCLE). Anti-Ro antibodies were discovered by Clark et al. ${ }^{30}$ and were then used as molecular probes to determine that the Ro complex includes the Ro60 ribonucleoprotein. Ro60 displays a donut-shaped form and associates with small cytoplasmic Y RNAs. Interestingly, Ro60, which is expressed in the nucleus and cytoplasm of lymphoid cells, also binds to RNAs that are incorrectly edited and cannot be translated. Ro60 has also been implicated in 5S rRNA editing and in the regulation of micro (mi) RNA biogenesis and RNA derivatives. ${ }^{31-37}$ Ro52 is another component of the Ro complex. Interestingly, this ribonucleoprotein contains zinc finger domains and a leucine zipper. Ro52 is encoded by a different gene than Ro60 and has different features and functions, such as binding to various DNA and RNA molecules. $^{38,39}$ Ro52 possesses two sequences at the carboxyl terminus (residues 365-382 and 380396) that share partial homology with the 5HT4A serotonin receptor. ${ }^{40}$ These receptors are involved in cardiovascular stimulation and consequently participate in arrhythmias; therefore, 5-HT4A receptors are widely expressed in the atrial tissue of fetal hearts. ${ }^{41}$ These molecular data are of clinical importance for understanding the pathophysiology of CHB. Another component of the Ro complex is the erythrocytederived Ro54 protein, which is not relevant in NL syndromes. La/SSA is a $48-\mathrm{kDa}$ ribonucleoprotein that forms a complex with Ro60 through a small YRNA. The La antigen participates in RNA maturation as a transcription termination factor of RNA polymerase III. ${ }^{31,32}$

\section{Clinical spectrum of neonatal diseases induced by maternal antinuclear antibodies}

Different neonatal pathologies are induced by maternal ANAs, including NL with or without CHB. Other cases of NL might develop hepatobiliar involvement and/or hematologic symptoms such as cytopenias.

The skin manifestations of NL appear at birth or within a few weeks after birth, and these conditions might persist for 16 weeks. ${ }^{42}$ Primary cutaneous lesions are erythematous papules distributed on the face and scalp, but sometimes the plaques are scattered. Newborns exhibit periorbital erythema, referred to as owl eyes, and these babies might display polycyclic lesions mimicking those observed in SCLE. At the onset or during exacerbation, the appearance of erythematous lesions is independent of photo exposure. Other less common skin lesions include petechiae, telangiectasia and cutis marmorata. ${ }^{29,43}$ Erythematous lesions eventually produce residual depigmentation and atrophy. The histopathology of these neonate skin conditions shows lesions mimicking SCLE or neutrophilic dermatitis, accompanied with mononuclear cell infiltration into the perivascular and periadnexal dermis and vacuolar degeneration of the basal cell layer. ${ }^{44,45}$ Lela Lee et al. extensively examined the pathophysiology of cutaneous NL using human foreskin grafted onto nude mice to assess the effect of human anti-Ro antibodies. ${ }^{46}$ These experiments demonstrated the pathogenic effects of anti-Ro antibodies, suggesting that antibody deposition induces ADCC cytotoxicity, leading to the inflammation and apoptosis of keratinocytes, which release intracellular Ro antigens, creating a pathophysiological loop. ${ }^{47,48}$

The cardiac manifestations of NL include variable degrees of $\mathrm{CHB}$, which is manifested as intrauterine bradycardia or low heart rates at birth. These anomalies persist for days or months, depending on the extent of the blockade, and when fibrosis of the atrial node is present, the blockage is permanent. In firstdegree atrioventricular block (AVB), the cardiac rate normalization is correlated with maternal autoantibody elimination from neonate circulation. Nevertheless, in thirddegree AVB, the permanent damage in the neonatal conduction system might require a pacemaker. CHB is a rare disease, affecting 1 in 20,000 live births, and in most cases, CHB results from inflammation of the AV node, which impedes the normal conduction of the electrical impulse to the ventricle. CHB can be associated with mesothelioma or structural cardiac abnormalities, such as isomerism or atrioventricular canal defects, but in $90 \%$ of cases, CHB reflects the transfer of maternal anti-Ro/La antibodies. ${ }^{49}$ The association of anti-Ro antibodies with CHB is highly specific, as the prevalence of anti-Ro in pregnant women is low, ranging from 0.8 to $1 \%$ in Caucasians $^{50,51}$ and $0.2 \%$ in Latin-American mestizo. ${ }^{52}$ The presence of anti-Ro/La antibod- ies in pregnant women has been associated with low fetal heart rate, suggesting the possibility of $\mathrm{CHB}$, and this suspicion must be documented using a fetal echocardiogram. In 2003 , Brucato et al. proposed the following criteria to determine whether an atrioventricular block is congenital: i) the blockage must be diagnosed in utero; and ii) when bradycardia is detected after birth, the diagnosis should be made during the first 27 days..$^{53}$ Newborns with CHB might have sinus bradycardia with abnormal QT space, as determined by electrocardiography. 54

In the $2.8 \%$ of pregnant women with antiRo/La antibodies, these antibodies might induce neonatal disease, and 3 to $15 \%$ of these babies will develop CHB. In the fetus, abnormal conduction must be antenatally assessed through Doppler sonography or noninvasive fetal electrocardiography, as both techniques yield good correlations, although noninvasive fetal electrocardiography shows greater specificity and sensitivity. ${ }^{55}$ In neonates with CHB, the outcome rarely results in dilated cardiomyopathy; however, this complication might occur regardless of pacemaker application, as these babies develop progressive heart failure after 11.6 months. Fortunately, few cases develop progressive deterioration and fatal ventricular failure, although some of these cases require heart transplantation. ${ }^{56,57}$ In 1957, Hogg described endocardial fibroelastosis as another cardiac manifestation of NL. ${ }^{58}$ This pathology primarily affects the left ventricle and causes severe ventricular dysfunction. This fibroelastosis has not been definitively associated with AVB, and neonates with this condition may develop skin manifestations as early as 1 month after birth. ${ }^{57}$ Congenital structural abnormalities have also been associated with the presence of maternal autoantibodies, although this association is incidental rather than causative. ${ }^{57}$

Experimental models for understanding the pathophysiology of CHB have been developed by different groups. The Buyon lab demonstrated toxic effects of maternal anti-Ro/La antibodies on the fetal cardiac conduction system. Using pregnant female Balb/c mice immunized with recombinant antigens, these researchers demonstrated that the offspring display CHB. Approximately $20 \%$ of the neonatal animals developed first-degree AVB after immunization with Ro60, and 7\% of the neonatal animals developed first-degree AVB after immunization with the La/SSB antigen. Interestingly, animals immunized with the Ro52 alpha isoform developed Mobitz I AVB, while immunization with the beta isoform induced complete AVB. ${ }^{59}$ Clinical and experimental data have clearly demonstrated that anti-Ro antibodies induce CHB. However, because the Ro complex is intracellular, it was unclear how the maternal antibodies targeted the fetal intracellular anti- 
gen. Using an in vitro system, Jill Buyon et al. demonstrated that Ro or La antigens were translocated to the cardiomyocyte cell surface through apoptotic membranes. Thus, the physiological programmed cell death observed during heart development favors the antigenic targeting of Ro/La antigens by maternal autoantibodies. Through this mechanism, autoantigens are externalized during apoptosis, ${ }^{60,61}$ and anti-Ro/La antibodies subsequently reach their target, releasing cytokines, such as TNF and TGF- $\beta$, that induce cardiomyocyte inflammation. In addition, TGF- $\beta$ induces the trans-differentiation of cardiac fibroblasts, leading to fibrosis and $\mathrm{AV}$ node scaring, ${ }^{62}$ and stimulates the plasminogen activator receptor, which feeds the fibrotic process. ${ }^{63}$ The toxic effect of anti-Ro52 antibodies on the conduction system is dose-dependent. Studies have demonstrated that these antibodies alter cardiomyocyte calcium homeostasis. Notably, Ro52 epitopes differ in each species. ${ }^{64-66}$ The sequences critical for CHB induction in humans have been deduced, but for ethical reasons, the effects of mutations have not been examined in vivo. Anti-Ro antibodies decouple the excitationcontraction cycles of the Cav1.3 subunit of Ltype calcium channels, producing contractile dysfunction. ${ }^{67,68}$ Cav1.3 knockout transgenic mice develop first-degree AVB, and the blockage increases after immunization with Ro or La antigens (Figure 2). ${ }^{69}$ To understand the evolution of $\mathrm{CHB}$, we must consider the ontogeny of the Ro (Figure 2) complex, which is detected at 12 weeks of development. ${ }^{70}$ The beta transcript of Ro52 is generated through alternative splicing and is fully expressed in the fetal heart at 14 weeks of development. Chan et al. showed that the expression of the beta transcript declines after birth and is replaced with the alpha transcript, characteristic of the adult heart. ${ }^{71}$ Thus, considering the fate of the alpha transcript of Ro52, the risk for CHB increases from 18 to 24 weeks of development. ${ }^{72}$ Clinically, CHB has two stages: the first stage occurs from 18 to 24 weeks and is characterized by a normal fetal heart rate; the second stage, which is characterized by bradycardia, occurs a few weeks later. If AVB is not properly treated during the second stage, then the blockage might progress to complete AVB. ${ }^{73}$

The management of $\mathrm{CHB}$ includes the administration of parenteral steroids, such as dexamethasone or betamethasone, with good results. The intravenous administration of $\operatorname{IgG}$ is also therapeutically successful. ${ }^{74,75}$ In the case of complete AVB, the newborn would require pacemaker implantation; however, some babies may develop dilated cardiomyopathy, and cardiac transplantation is the last alternative to preserve the life of the neonate..$^{56}$ Although CHB has been associated with significant morbidity and mortality, the survival rate after 3 years is approximately $80 \%$. When a child with CHB becomes an adult, their CHB history should be considered for managing associated comorbidities.49,76 Concerning maternal treatment during pregnancy, the administration of hydroxychloroquine together with a low dose of prednisone might exert protective effects. ${ }^{77}$ Other miscellaneous manifestations of NL include hepatobiliary damage, which can be associated with jaundice, cholestatic hepatitis, and occasional thrombocytopenia; anemia; hyperbilirubinemia; and elevated transaminase levels. The hepatic dysfunction occurs in utero or appears shortly after birth, and clinical and biochemical parameters typically return to normal after approximately eight weeks. Hemocytopenia has also been reported in $10 \%$ of NL cases, among which neutropenia and/or transitory lymphopenia are frequent. ${ }^{29,78,79}$ Other rare manifestations of NL occur in the central nervous system (CNS), including seizures, CNS bleeding, or myelopathy. ${ }^{80-83}$

\section{Conclusions}

Lupus is a common disease in women of reproductive age. Thus, it is important to consider the possibility of neonatal syndromes induced through ANA maternal autoantibodies, including NL with or without CHB. As NL with CHB must be detected prenatally, adequate clinical, serological, and echocardiographic screening must be performed in all pregnant women with lupus or Sjögren's syndrome. After the pregnancy is resolved, systematic postnatal maternal tracking must be performed to determine the likelihood of NL in subsequent pregnancies. ${ }^{84-87}$ Moreover, this review acknowledges those who have performed studies on NL, particularly Tom Provost, who recently passed away. Indeed, his original contribution to these studies triggered a cascade of sophisticated research, revealing the cellular and molecular mechanisms underlying the pathogenic role of maternal antiRo/la antibodies in the induction of $\mathrm{NL}$ pathologies.

\section{References}

1. Hargraves MM, Richmond H, Morton R. Presentation of two bone marrow elements; the tart cell and the L.E. cell. Proc Staff Meet Mayo Clin 1948;23:25-8.

2. Tsokops GC. Systemic lupus erythematosus. N Engl J Med 2011;365:2110-21.

3. Mok CC, Wong RWS. Pregnancy in systemic lupus erythematosus. Postgrad Med J 2001;77:157-65.

4. Martinez-Rueda J0, Arce-Salinas CA,
Kraus A, et al. Factors associated with fetal losses in severe systemic lupus erythematosus. Lupus 1996;5:113-9.

5. Saavedra MA, Cruz-Reyes C, Vera-Lastra 0 , et al. Impact of previous lupus nephritis on maternal and fetal outcomes during pregnancy. Clin Rheumatol 2012;31:813-9.

6. Scotti M, Kmita M. Recruitment of 5' Hoxa genes in the allantois is essential for proper extra-embryonic function in placental mammals. Development 2012;139:731-9.

7. Sood R, Zehnder JL, Druzin ML, Brown PO. Gene expression patterns in human placenta. Proc Natl Acad Sci USA 2006;103: 5478-83.

8. Williams Z. Inducing tolerance to pregnancy. N Engl J Med 2012;367:1159-61.

9. Samstein RM, Josefowicz SZ, Arvey A, et al. Extrathymic generation of regulatory $\mathrm{T}$ cells in placental mammals mitigates maternal-fetal conflict. Cell 2012;150:2938.

10. Zheng Y, Josefowicz SZ, Chaundhry A, et al. Role of conserved non-coding DNA elements in the Foxp3 gene in regulatory Tcell fate. Nature 2010;463:808-12.

11. Jurka J, Zietkiewicz E, Labuda D. Ubiquitous mammalian-wide interspersed repeats (MIRs) are molecular fossils from the mesozoic era. Nucleic Acids Res 1995;23:170-5.

12. Palmeira P, Quiniello C, Silveira-Lessa AL, et al. IgG placental transfer in healthy and pathological pregnancies. Clin Dev Immunol. 2012;2012:985646.

13. Saji F, Samejina Y, Kaimura S, Koyama M. Dynamics of immunoglobulins at the fetomaternal interface. Rev Reprod 1999;4:819.

14. Guzman L, Avalos E, Ortiz R, et al. Placental abnormalities in systemic lupus erythematosis: in situ deposition of antinuclear antibodies. J Rheumatol 1987;14: 924-9.

15. Sakui H, Yoshimura Y, Tada S, et al. [Serological and immunohistochemical studies in pregnant women with systemic lupus erythematosus]. Nihon Sanka Fujinka Gakkai Zasshi 1989;41:249-56. [Article in Japanese].

16. Abramowsky C, Vegas ME, Swinehart G, Gyves MT. Decidual vasculopathy of the placenta in lupus erythematosus. N Engl J Med 1980;303:668-72.

17. Grennan DM, McCormick JN, Wojtacha D, et al. Immunological studies of the placenta in systemic lupus erythematosus. Ann Rheum Dis 1978;37:129-34.

18. Bridge R, Foley F. Placental transmission of the lupus erythematosus factor. Am J Med Sci 1954;227:1-8.

19. Berlyne GM, Short IA, Vickers CF. Placental transmisson of the LE factor, report of two cases. Lancet 1957;273:15-6. 
20. Burman D, Oliver RA. Placental transfer of the lupus erythematosus factor. J Clin Pathol 1958;11:43-4.

21. Nathan DJ, Snapper I. Simultaneous placental transfer of factors responsable for LE cell formation and trombocitopenia. Am J Med 1958;25:647-53.

22. Beck JS, Oakley CL, Rowell NR. Transplacental passage of antinuclear antibody. Study in infants of mothers with systemic lupus erythematosus. Arch Dermatol 1966;93:656-63.

23. Guzmán-Enríquez L, Avalos-Díaz E, Herrera-Esparza R. Transplacental transfer of human antinuclear antibodies in mice by injection of lupus IgG in pregnant animals. J Rheumatol 1990;17:52-6.

24. McCuistion CH, Schoch EP. Possible discoid lupus erythematosus in newborn infant: report of a case with subsequent development of acute systemic lupus erythematosus in mother. AMA Arch Derm Syphilol 1954;70:782-5.

25. Kephart DC, Hood AF, Provost TT. Neonatal lupus erythematosus: new serologic findings. J Invest Dermatol 1981;77:331-3.

26. Weston WL, Harmon C, Peebles C, et al. A serological marker for neonatal lupus erythematosus. Br J Dermatol 1982;107;37782.

27. Provost TT, Herrera-Esparza R, Diaz LA. Nucleoprotein autoantibodies in lupus erythematosus. $\mathrm{J}$ Invest Dermatol 1985;85:133s-9s.

28. Chameides L, Truex RC, Vetter V, et al. Association of maternal systemic lupus erythematosus with congenital complete heart block. N Engl J Med 1977;297:1204-7.

29. Lee L. Clinical spectrum of neonatal lupus. Arch Dermatol Res 2009;301:107-10.

30. Clark G, Reichlin M, Tomasi TB Jr. Characterization of a soluble cytoplasmic antigen reactive with sera from patients with systemic lupus erythmatosus. J Immunol 1969;102:117-22.

31. Wolin SL, Steitz JA. The Ro small cytoplasmic ribonucleproteins: identification of the antigenic protein and its binding site on the Ro RNAs. Proc Natl Acad Sci USA 1984;81:1996-2000.

32. Herrera-Esparza R, Provost TT, Diaz LA. Molecular characterization of Ro(SSA) and La(SSB) proteins. J Rheumatol 1986;13:327-30.

33. Wolin SL, Reinisch KM. The Ro $60 \mathrm{kDa}$ autoantigen comes into focus: interpreting epitope mapping experiments on the basis of structure. Autoimmun Rev 2006;5:367-72.

34. Verhagen AP, Pruijn GJ. Are the Ro RNPassociated Y RNAs concealing microRNAs? Y RNA-derived miRNAs may be involved in autoimmunity. Bioessays 2011;33:674-82.

35. O'Brien CA, Wolin SL. A possible role for the $60-\mathrm{kDa}$ Ro autoantigen in a discard pathway for defective 5S rRNA precursors. Genes Dev 1994;8:2891-903.

36. Campos-Almaraz M, Fraire-Velázquez $\mathrm{S}$, Moreno J, et al. The 5S rRNA is associated with Ro60 ribonucleoprotein and is co-precipitated with hYRNAs by anti-Ro antibodies. Autoimmunity 1999;31:95-101.

37. Lopez Robles E, Herrera-Esparza R, AvalosDiaz E. Cellular localization of the Ro/SS-A antigen. Clin Rheumatol 1986;5:33-8.

38. Ben-Chetrit E, Chan EKL, Sullivan KF, Tan EM. A $52 \mathrm{kD}$ protein is a novel component of the SS-A/Ro antigenic particle. J Exp Med 1988;167:1560-71.

39. Itoh K, Itoh Y, Frank MB. Protein heterogeneity in the human Ro/SSA ribonucleoproteins. The 52 - and $60 \mathrm{kD}$ autoantigens are encoded by separate genes. J Clin Invest 1991;87:177-86.

40. Karnabi E, Boutjdir M. Role of calcium channels in congenital heart block. Scand J Immunol 2010;72:226-34.

41. Galindo-Tovar A, Vargas ML, Escudero E, Kaumann AJ. Ontogenic changes of the control by phosphodiesterase- 3 and -4 of the 5 -HT responses in porcine heart and relevance to human atrial 5-HT4 receptors. Br J Pharmacol 2009;156:237-49.

42. Neiman AR, Lee LA, Weston WL, Buyon JP. Cutaneous manifestations of neonatal lupus without heart block: characteristics of mothers and children enrolled in a national registry. J Pediatr 2000;137:67480.

43. Weston WL, Morelli JG, Lee LA. The clinical spectrum of anti-Ro-positive cutaneous neonatal lupus erythematosus. J Am Acad Dermatol 1999;40:675-81.

44. Lee SH, Roh MR. Targetoid lesions and neutrophilic dermatosis: an initial clinical and histological presentation of neonatal lupus erythematosus. Int $\mathrm{J}$ Dermatol 2014;53:764-6.

45. Peñate Y, Guillermo N, Rodríguez J, et al. Histopathologic characteristics of neonatal cutaneous lupus erythematosus. J Cutan Pathol 2009;36:660-7.

46. Lee LA, Weston WL, Krueger GG, et al. An animal model of antibody binding in cutaneous lupus. Arthritis Rheum 1986;29:7828.

47. Herrera-Esparza R, Villalobos R, Bollain-YGoytia JJ, et al. Apoptosis and redistribution of the Ro autoantigen in Balb/c mouse like in subacute cutaneous lupus erythematosus. Clin Dev Immunol 2006;13:163-6.

48. Yu HS, Chiang LC, Chang $\mathrm{CH}$, et al. The cytotoxic effect of neonatal lupus erythematosus and maternal sera on keratinocyte cultures is complement-dependent and can be augmented by ultraviolet irradiation. Br J Dermatol 1996;135:297301.
49. Capone C, Buyon JP, Friedman DM, Frishman WH. Cardiac manifestations of neonatal lupus: A review of autoantibody associated congenital heart block and its impact in an adult population. Cardiol Rev 2012;20:72-6.

50. Calmes M, Bartolomew BA. SS-A (Ro) antibody in random mother-infant pairs. $\mathrm{J}$ Clin Pathol 1985;38:73-5.

51. Harmon CE, Cuff C, Norris D, Weston W. The frequency of antibodies to the SSA (Ro) antigen in pregnant sera. Arthritis Rheum 1984;27:S20.

52. Guzmán L, Martínez P, Gaytán G, et al. Anti-Ro antibodies in healthy mothers and their newborns. Clin Exp Rheumatol 1987;5:93-4.

53. Brucato A, Jonzon A, Friedman D, et al. Proposal for a new definition of congenital complete atrioventricular block. Lupus 2003;12:427-35.

54. Brucato A, Cimaz R, Stramba-Badiale M. Neonatal lupus. Clin Rev Allergy Immunol 2002;23:279-99.

55. Gardiner HM, Belmar C, Pasquini L, et al. Fetal ECG: a novel predictor of atrioventricular block in anti-Ro positive pregnancies. Heart 2007;93:1454-60.

56. Moak JP, Barron KS, Hougen TJ, et al. Congenital heart block: development 0 late-onset cardio-myopathy, a previously underappreciated sequel. J Am Coll Cardiol 2001;37:238-42.

57. Costedoat-Chalumeau N, Amoura Z, Villain E, et al. Anti-SSA/Ro antibodies and the heart: more than complete congenital heart block? A review of electrocardiographic and myocardial abnormalities and of treatment options. Arthritis Res Ther 2005;7:69-73.

58. Hogg GR. Congenital, acute lupus erythematosus associated with subendocardial fibroelastosis; report of a case. Am J Clin Pathol 1957;28:648-54.

59. Miranda-Carús ME, Boutjdir M, Tseng CE, et al. Induction of antibodies reactive with SSA/Ro-SSB/La and development of congenital heart block in a murine model. $\mathrm{J}$ Immunol 1998;161:5886-92.

60. Miranda-Carus ME, Tseng CE, Rashbaum W, et al. Accessibility of SSA/Ro and SSB/La antigens to maternal autoantibodies in apoptotic human fetal cardiac myocytes. J Immunol 1998;161:5061-9.

61. Miranda-Carús ME, Askanase AD, Clancy RM, et al. Anti-SSA/Ro and anti-SSB/La autoantibodies bind the surface of apoptotic fetal cardiocytes and promote secretion of TNF- $\alpha$ by macrophages. J Immunol 2000;165:5345-51.

62. Clancy RM, Askanase AD, Kapur RP, et al. Transdifferentiation of cardiac fibroblasts, a fetal factor in anti-SSA/Ro-SSB/La antibody-mediated congenital heart block. J 
Immunol 2002;169:2156-63.

63. Briassouli P, Rifkin D, Clancy RM, Buyon JP. Binding of anti-SSA antibodies to apoptotic fetal cardiocytes stimulates urokinase plasminogen activator (uPA)/uPA receptor-dependent activation of TGF- $\beta$ and potentiates fibrosis. J Immunol 2011;187:5392-401.

64. Ambrosi A, Dzikaite V, Park J, et al. AntiRo52 monoclonal antibodies specific for amino acid 200-239, but not other Ro52 epitopes, induce congenital heart block in a rat model. Ann Rheumatic Dis 2012;71:448-54.

65. Salomonsson S, Sonesson SE, Ottosson L, et al. Ro/SSA autoantibodies directly bind cardiomyocytes, disturb calcium homeostasis, and mediate congenital heart block. J Exp Med 2005;201:11-7.

66. Eftekhari P, Roegel JC, Lezoualch F, et al. Induction of neonatal lupus in pups of mice immunized with synthetic peptides derived from amino acid sequences of the serotoninergic 5-HT4 receptor. Eur J Immunol 2001;31:573-9.

67. Xiao GQ, Qu Y, Hu K, Boutjdir M. Downregulation of L-type calcium cannel in pups born to $52 \mathrm{kDa} \mathrm{SSA} / \mathrm{Ro}$ immunized rabbits. FASEB J 2001;1539-45.

68. Ambrosi A, Wahren-Herlenius M. Congenital heart block: evidence for a pathogenic role of maternal autoantibodies. Arthritis Res Ther 2012;14:208.

69. Karnabi E, Qu Y, Mancarella S, Boutjdir M. Rescue and worsening of congenital heart block-associated electrocardiographic abnormalities in two transgenic mice. $\mathrm{J}$ Cardiovasc Electrophysiol 2011;22:922-30.

70. Fraire-Velázquez S, Herrera-Esparza R,
Villalobos-Hurtado R, Avalos-Díaz E. Ontogeny of Ro hYRNAs in human heart. Scand J Rheumatol 1999;28:100-5.

71. Chan EK, Di Donato F, Hamel JC, et al. 52$\mathrm{kD}$ SS-A/Ro: genomic structure and identification of an alternatively spliced transcript encoding a novel leucine zipperminus autoantigen expressed in fetal and adult heart. J Exp Med 1995;182:983-92.

72. Ambrosi A, Salomonsson S, Eliasson H, et al. Development of heart block in children of SSA/SSB-autoantibody-positive women is associated with maternal age and displays a season-of-birth pattern. Ann Rheumatic Dis 2012;71:334-40.

73. Wojakowski A, Izbizki G, Carcano ME, et al. Fetal doppler mecanical PR interval: correlation with fetal heart rate, gestational age and fetal sex. Ultrasound Obstet Gynecol 2009;34:538-42.

74. Buyon JP, Waltuck J, Kleinman C, Copel J. In utero identification and therapy of congenital heart block. Lupus 1995;4:116-121.

75. D. Friedman, C. Llanos, P. M. Izmirly, et al. Evaluation of fetuses in the preventive IVIG therapy for congenital heart block (PITCH) study. Arthritis Rheum 2010;62:1138-46.

76. Buyon JP, Hiebert R, Copel J, et al. Autoimmune-associated congenital heart block: demographics, mortality, morbidity and recurrence rates obtained from a national neonatal lupus registry. J Am Coll Cardiol 1998;31:1658-66.

77. Tunks RD, Clowse ME, Miller SF, et al. Maternal autoantibody levels in congenital heart block and potential prophylaxis with antiinflammatory agents. Am J Obstet Gynecol 2013;208;64.e1-7.
78. Lin SC, Shyur SD, Huang LH, et al. Neonatal lupus erythematosus with cholestatic hepatitis. J Microbiol Immunol Infect 2004;37:131-4.

79. Hon KL, Leung AK. Neonatal lupus erythematosus. Autoimmune Dis 2012;2012:301274.

80. Cabañas F, Pellicer A, Valverde E, et al. Central nervous system vasculopathy in neonatal lupus erythematosus. Pediatr Neurol 1996;15:124-6.

81. Kaye EM, Butler IJ, Conley S. Myelopathy in neonatal and infantile lupus erythematosus. J Neurol Neurosurg Psychiatry 1987;50:923-6.

82. Prendiville JS, Cabral DA, Poskitt KJ, et al. Central nervous system involvement in neonatal lupus erythematosus. Pediatric Dermatol 2003;20:60-7.

83. Chen CC, Huang JL, Hsu JF, et al. Neonatal lupus complicated by hemorrhagic stroke. Lupus 2012;21:1582-5.

84. Carvalheiras G, Faria R, Braga J, Vasconcelos C. Fetal outcome in autoimmune diseases. Autoimmun Rev 2012;11: A520-30.

85. Wisuthsarewong W, Soongswang J, Chantorn R. Neonatal lupus erythematosus: clinical character, investigation, and outcome. Pediatr Dermatol 2011;28:11521.

86. Buyon JP. Updates on lupus and pregnancy. Bull NYU Hosp Jt Dis 2009;67:271-5.

87. Rivera TL, Izmirly PM, Birnbaum BK, et al. Disease progression in mothers of children enrolled in the Research Registry for Neonatal Lupus. Ann Rheum Dis 2009;68: 828-35. 